\title{
Obesity: the new metabolic frontier
}

\author{
Yokaichiya, D.K. ${ }^{1}$; Araujo, D.R. ${ }^{1}$, Silva, J.A. ${ }^{1}$, Torres, B.B. ${ }^{2}$ and Galembeck, E. ${ }^{1}$
}

${ }^{1}$ Depto de Bioquímica, IB - Unicamp, C.P. 6109, CEP 13083-970, Campinas SP; ${ }^{2}$ Depto de Bioquímica, IQ USP, C.P. 26077, CEP 05508-900, São Paulo SP

Working on active learning strategies for web based courses, the Biochemical Education Research group from USP and Unicamp's departments of Biochemistry has developed the educational software Obesity: the new metabolic frontier. The software was designed to be used as a major reference to study this subject on 2003 Biochemistry of Nutrition course, and was based on the most recent publications about obesity, specially concerning the leptin role in this metabolic disturb. The most relevant characteristic of this software is the use of animated models to represent the cellular response and the presentation of many other mechanisms involved in obesity. We also intended to focus the relationship between leptin and other mechanisms that lead to obesity. The teaching strategy consisted in providing the students with the software and a text about Obesity. After few days, they should discuss the topic in a two-hour synchronous discussions chat-rooms (specially designed for this purpose), with a Teaching Assistant's (TA) help. After the discussion, the students were asked to answer an evaluation survey about the activity and the software efficience to the learning process. The TAs were asked to evaluate the software as a tool to help in teaching process. In the following week the students had to go back to the chat-rooms for an online synchronous test. The results of this experience (students and TAs satisfaction) were very clear and stimulated us to go on with software development and to improve the use of this kind of educational tool in Biochemistry classes.

\section{Supported by: FAPESP}

